\title{
Traumatic Retropharyngeal Abscess of Insidious Onset-A Case Report and Literature Review
}

\author{
Shuaib Kayode Aremu \\ ENT Department, Federal Teaching Hospital Ido-Ekiti/Afe Babalola University, Ado-Ekiti, Nigeria \\ Email: shuaib.aremu@gmail.com
}

How to cite this paper: Aremu, S.K. (2019) Traumatic Retropharyngeal Abscess of Insidious Onset-A Case Report and Literature Review. Case Reports in Clinical Medicine, 8, 57-61.

https://doi.org/10.4236/crcm.2019.84008

Received: March 22, 2019

Accepted: April 13, 2019

Published: April 16, 2019

Copyright $\odot 2019$ by author(s) and Scientific Research Publishing Inc. This work is licensed under the Creative Commons Attribution International License (CC BY 4.0).

http://creativecommons.org/licenses/by/4.0/

\begin{abstract}
Retropharyngeal abscess is an abscess of the deep spaces in the neck which if not treated urgently can be life-threatening as a result of airway compromise. It is important to detect and treat very early. It may arise in pediatrics from direct neck trauma which is not very common and fishbone impaction. Direct anterior neck trauma resulting in insidious retropharyngeal abscess has not been widely reported.
\end{abstract}

\section{Keywords}

Retropharyngeal, Abscess, Trauma, Neck Spaces

\section{Introduction}

The facial envelope which surrounds the neck structures is partitioned into may potential spaces of which retropharyngeal space is one of them [1]. Retropharyngeal abscess is an abscess of the deep spaces in the neck which if not treated urgently can be life-threatening as a result of airway compromise. Early detection and treatment are therefore very essential. It may arise in pediatrics from direct neck trauma which is not very common and fishbone impaction. However other risk factors causing it include endotracheal intubation, surgery, laryngoscopy and placement of nasogastric tube [2]. Here we present a case report of retropharyngeal abscess arising from a direct hit on the anterior neck of a 7-yearold boy by a car seat.

\section{Case Report}

A 7-year-old boy who presented at the emergency pediatric unit of Federal Teaching Hospital, Ido-Ekiti with 6 days history of anterior neck pain following 
blunt neck trauma sustained by hitting his neck against the edge of a seat while on the school bus. There was associated gradual onset of progressive anterior neck swelling, hoarseness, dysphagia, initially to solid then semisolid food and 2 days history of gradual onset of intermittent fever which became high grade, but no chills nor rigor. 3 hours prior to presentation he was noticed to have difficulty in breathing at rest, noisy breathing and neck stiffness.

Examination revealed an acutely ill-looking boy in obvious respiratory distress with biphasic stridor, forward extending neck posture, dehydrated and febrile but not pale, nor anicteric, and not cyanosed.

The Vital signs were: $\mathrm{T}-37.9^{\circ} \mathrm{C}, \mathrm{RR}-28 / \mathrm{min}, \mathrm{PR}-128 \mathrm{~b} / \mathrm{min}, \mathrm{BP}-110 / 70$ mmHg.

The Oral cavity revealed hyperemic and bulging posterior pharyngeal wall (Figure 1).

There was diffuses tender anterior neck swelling with no palpable trachea but multiple palpable cervical lymph nodes.

Full blood count: PCV 53\%, WBC $18 \times 10^{9} / \mathrm{L}$ (with relative neutrophilia). E/U/Cr: within normal range. (Na: $136 \mathrm{mEq} / \mathrm{L}$, K: $3.8 \mathrm{mEq} / \mathrm{L}$, Urea: $8 \mathrm{mg} / \mathrm{dl}$, Creatine: $0.615 \mathrm{mg} / \mathrm{dl})$.

X-ray soft tissue neck (Figure 2) showed widening of the prevertebral space

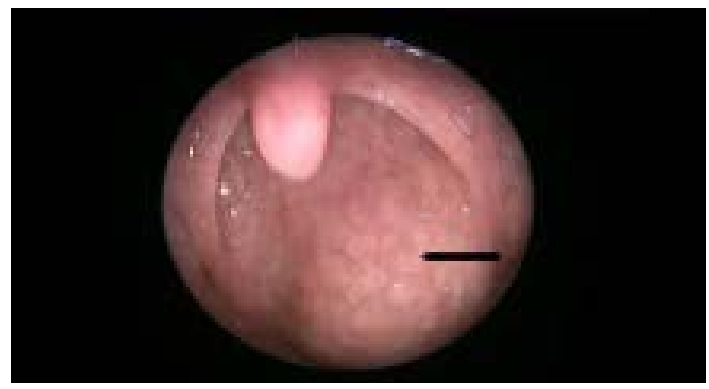

Figure 1. A bulge of the posterior pharyngeal wall.

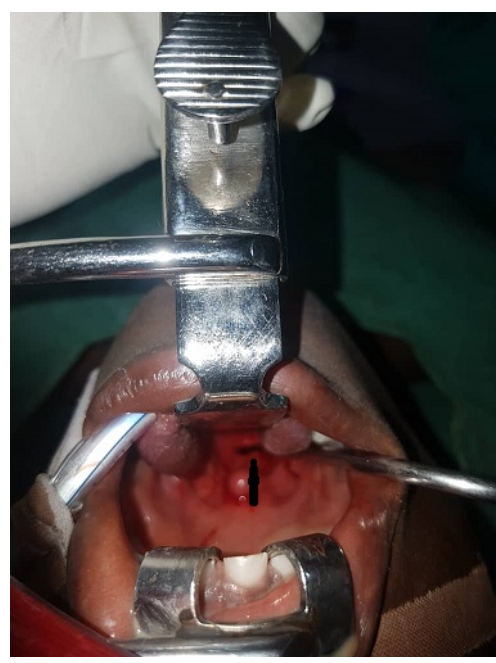

Figure 2. Widening of the prevertebral space with compression of the airway indicated by the black arrow. 
by collections and compression of the laryngeal inlet.

$\mathrm{He}$ had an emergency examination under anesthesia with Incision and Drainage of the abscess (Figure 3).

The Pus drained was about $30 \mathrm{mls}$, thick and foul-smelling but yielded no growth possibly due to the fact that he had been on self antibiotics medication since the day of the trauma. He did well postoperatively with the resumption of normal voice and breathing. $3^{\text {rd }}$-day postoperative $\mathrm{x}$-ray was essentially normal (Figure 4). He was discharged on the $5^{\text {th }}$ day.

\section{Discussion}

Retropharyngeal abscess is often seen in children under the age of 4 - 5 years but can be seen in any age group. Space lies behind the pharynx between the buccopharyngeal fascia, covering the constrictor muscle and the prevertebral fascia, extending from the skull base to the tracheal bifurcation. Suppuration of Retropharyngeal

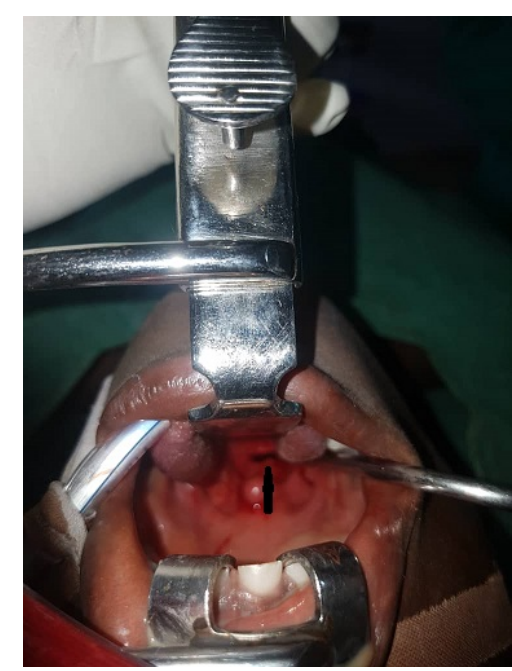

Figure 3. Intra-operatively, Incision and Drainage indicated by the black arrow.

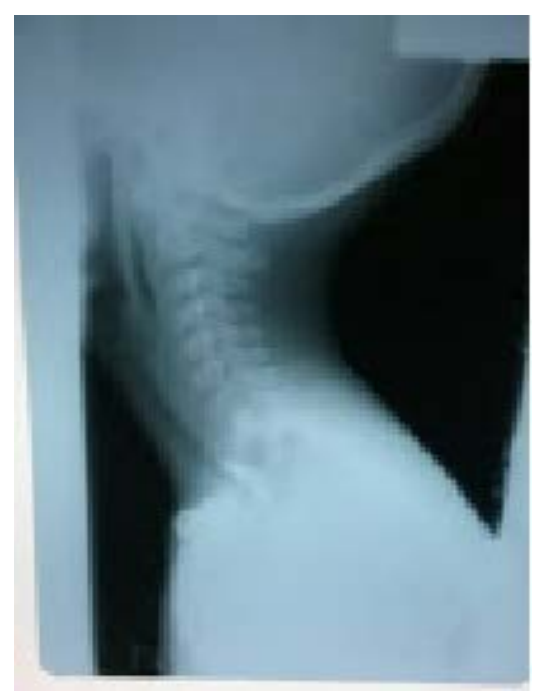

Figure 4. Post-operative X-ray showing almost normal features. 
lymph nodes which drain the nasopharynx, oropharynx and the tonsils is commonly responsible for the abscess in children.

Of the deep neck space infections, the incidence of retropharyngeal infections is less than that of other infections like peritonsillar infections [3]. Traumatic retropharyngeal abscess has been described to arise secondarily from blunt oropharyngeal trauma in a road traffic accident [4], by a blunt object like an umbrella', or impacted foreign bodies like safety pins [5]. In our study, a direct hit on the anterior neck was the cause. This mechanism has not been commonly reported. This progressive nature of the presentation over 6 days period pointed to the fact that there might have been the possibility of minimal bleed in the retropharyngeal space with hematoma collections and subsequent abscess formation. The 6-day history of hoarseness and the 3-hour history of dyspnoea were as a result of the mild blunt laryngeal trauma initially and later by the airway compromise from the pressure from the retropharyngeal abscess (Figure 2). Subcutaneous emphysema with the abscess was described in a case of oropharyngeal trauma by Siou G et al. [6] but this is not seen in our own study. Successful management of retropharyngeal abscess largely depends on early detection of the abscess. A careful and detail history of trauma and clinical features such as neck pain, stiffness, change in voice and in severe cases drolling of saliva and bulging of the posterior pharyngeal wall are pointers to the condition. Radiological (Plain X-ray of CT scan) finding of a widening of the prevertebral space (Figure 2) confirms the diagnosis. Empirical use of broad-spectrum antibiotics and urgent Examination under anesthesia with incision and drainage is the hallmark of treatment. Surgical approaches are either Trans-oral, which is the common use approach or external approach. The trans-oral approach is effective for abscess localized to the pharynx without lateral pharyngeal extension. This is the approach used in this index patient.

Deep neck infections may be associated with life-threatening complications such as airway obstruction, jugular thrombophlebitis, carotid rupture, and mediastinitis. These complications can be avoided by vigilance, adequate evaluation, prompt diagnosis, and aggressive management [7].

\section{Conclusion}

Post-traumatic retropharyngeal abscess can be insidious in onset with gradual airway compromise which if not detected and managed timely and adequately can result in mortality.

\section{Ethical Approval}

Ethical approval was obtained from the ethical and research committee of our institution.

\section{Conflicts of Interest}

The author declares no conflicts of interest regarding the publication of this pa- 
per.

\section{References}

[1] Singh, I., Chanda, R., Gupta, K.B. and Yadav, S.P. (2003) Fatal Pyothorax: A Rare Complication of Retropharyngeal Abscess. Indian Journal of Chest Disease and AIlied Science, 45, 265-268.

[2] Bayer, S., Eldon, J. and Gay, I. (1990) Retropharyngeal Abscess caused by Traumatic Perforation by Fish Bone. Annals of Otology, Rhinology \& Laryngology, 99, 927-928.

[3] Ungkanon, T.K., Yellon, R.F., Weissman, J.L., Casselbrant, M.L., Gonsazelez-Valdepana, H. and Bluestone, C.D. (1995) Head and Neck Space Infections in Infants and Children. Otolaryngology Head and Neck Surgery, 112, 375-382. https://doi.org/10.1016/S0194-5998(95)70270-9

[4] Selbst, S.M., Fein, J.A., Friday, J., Scribano, P. and Magardino, T. (1998) Retropharyngeal Abscess after Blunt Trauma in an Adolescent. Pediatric Emergency Care, 14, 406-408. https://doi.org/10.1097/00006565-199812000-00007

[5] Shivakumar, M., NaikAshok, S., Prashant, K.B., Yogesh, B.S. and Hangal Girish, F. (2004) Foreign Bodies in Upper Aerodigestive Tract. Indian Journal Pediatrics, 71, 689-693. https://doi.org/10.1007/BF02730655

[6] Siou, G. and Yates, P. (2000) Retropharyngeal Abscess as a Complication of Oropharyngeal Trauma in an 18 Month Child. Journal of Laryngology and Otology, 114, 227-228. https://doi.org/10.1258/0022215001905193

[7] Awasthi, S.K., Dutta, A. and Verghese, B.K. (2006) A Case of Post Traumatic Retropharyngeal Abscess. Indian Journal of Otolaryngology and Head and Neck Surgery, 58. 